\title{
Evaluation of risk factors predicting surgical treatment in tuboovarian
}

\section{abscess cases}

\author{
Bora Çoşkun ${ }^{1}$, Coşkun Şimşir ${ }^{2}$
}

\begin{abstract}
Objective: The main outcome measure of the present study was to find out the predictive factors affecting the need for surgery in patients diagnosed with tuboovarian abscess (TOA). We also examined the success of different medical treatment regimens in those patients.

Material and Methods: This was a retrospective clinical study performed on 96 TOA patients who were treated in the current hospital between August 2015 and August 2019. All patients underwent physical examination and ultrasonographic imaging with some laboratory tests to investigate the presence of TOA. Two different medical treatment regimens were administered as recommended by the international guidelines after the initial diagnoses. Patients with worsening clinical and/or laboratory findings and/or who did not respond to medical treatment were taken to surgery. Predictive factors for surgical intervention and success rates of medical treatment regimens were evaluated.
\end{abstract}

Results: White blood cell (WBC) levels $\geq 16000$ and abscess size $\geq 7 \mathrm{~cm}$ was strongly correlated with the requirement for surgery. The 94 patients received the Regimen 1 . Six patients underwent surgery urgently when they were under medical treatment. Regimen 1 failed in 21 (22.34 \%) patients out of 94, Regimen 2 was shifted to. Six patients (28.5\%) out of 21 underwent surgery because of treatment failure with Regimen 2 . Recovery was achieved in the remaining 15 $(71.4 \%)$ patients.

Conclusion: The success of medical TOA treatment was found to be high. Therefore, medical treatment can be applied first, except in case of acute abdomen. It was found that WBC and abscess diameter in patients with TOA in admission were the most important factors affecting the need for surgery. The factors affecting the duration of medical treatment were found to be age, WBC count, CRP (C-Reactive Protein), ESR (Erythrocyte Sedimentation Rate) and NLR (Neutrophil/Lymphocyte Ratio) levels.

Key words: Tuboovarian Abscess, Medical Treatment, Surgical Approach

\section{Introduction}

In patients staying in clinics with pelvic inflammatory disease (PID), prevalence of tuboovarian abscess (TOA), which is among the most serious complications of PID, is reported as $10-30 \%(1,2)$. Actual prevalence of PID can be difficult because of the ambiguity in the diagnosis of subclinical PID, which is one of the types of PID together with acute and subacute PID. Early start of sexual life, multiple sexual partners, not using barrier anticontraceptive and chlamydia or gonorrhea infections are among factors affecting the occurrence of PID (3).

The risk factors related to TOA resemble the risk factors of PID. Past PID in personal history is also a significant risk factor for TOA (4). Pelvic inflammatory disease will have long term complications including chronic abdominal pain, ectopic pregnancy and infertility in almost $25 \%$ of women because of delayed medical therapy because of varying clinical features and lack of specific laboratory tests (5).

Polymicrobial anaerobic and aerobic bacterial infections result in PID and TOA. Although Neisseria gonorrhoeae and Chlamydia trachomatis rarely grow in cultures in PID and TOA, they are the suspected facilitators $(6,7)$. Escherichia coli and Bacteroides species are the most commonly isolated organisms in TOA (8). TOA optimal approach is still controversial. In the treatment, oral antibiotics follow the classical intravenous antibiotic therapy. Surgery such as laparoscopy or laparotomy with drainage of the abscess, unilateral or bilateral adnexectomy, or hysterectomy will be required in case of failing medical 
treatment. Drainage with the guidance of imaging techniques or needle aspiration of the abscess is another approach for TOA treatment, and is combined with antibiotics(9). Center for Disease Control and Prevention recommends empiric broad-spectrum antibiotics for the medical therapy of TOA (10). If it is understood that antibiotic resistance is of question, surgery will be required. Our primary purpose in this study was to find out the predictive factors affecting the need for surgery and antibiotic resistance reported by the laboratory, and clinical and sonographic findings of patients diagnosed with TOA on admission. The second purpose was to investigate the success of medical treatment regimens. Thirdly, factors effective the duration of medical treatment were analyzed for medically-treated patients.

\section{Material and Methods}

This is a retrospective study conducted on 94 inpatients diagnosed with TOA in Ankara Liv Hospital, Obstetrics and Gynecology Department between August 2015 and August 2019. Approval of the ethical committee of our hospital was obtained for our study (Liv Hospital Ankara Local Ethical Committee Date: 09 August 2019 Approval Number: 2019/004-003) and Our study was conducted in accordance with the principles of the Declaration of Helsinki.

Physical examination and laboratory tests were carried out on patients with lower quadrant abdominal pain to investigate PID and TOA. At least 2 major criteria (lower abdominal quadrant tenderness, cervical motion tenderness, adnexal tenderness), and at least one minor criteria (body temperature $>38.3{ }^{\circ} \mathrm{C}$, cervicovaginal mucopurulent discharge, white blood cell (WBC)> 10 000/ml, erythrocyte sedimentation rate $(E S R)>15 \mathrm{~mm} /$ hour, C-reactive protein $(\mathrm{CRP})>10 \mathrm{mg} / \mathrm{L}$ and cervical infection with $\mathrm{N}$. gonorrhoeae or C. trachomatis (10) were required for the diagnosis of PID. An ultrasound examination was performed to diagnose TOA.

One of the two medical treatment regimens were administered as recommended by Sexually-transmitted diseases treatment guidelines, 2015 (11)

Regimen 1: Ampicillin (2 g IV every 6 hours) + Clindamycin (900 mg IV every 8 hours) + Gentamicin (2 $\mathrm{mg} / \mathrm{kg}$ loading dose then $1.5 \mathrm{mg} / \mathrm{kg}$ every 8 hours IV or IM)

Regimen 2: $\quad$ Levofloxacin (500 $\mathrm{mg}$ IV once daily) + Metronidazole (500 mg IV every 8 hours)

Initial therapy with Regimen 1 was administered for ten days. Upon observation of improvement in clinical and laboratory findings, the patient was discharged with the recommendation of Metronidazole (500 mg orally twice daily) + Doxycycline (100 mg orally twice daily) for 14 days.

In cases where Regimen I was not successful within 48-72 hours, Regimen 2 was administered for ten days more. In resistant cases (no improvement within 48 to 72 hours with Regimen 2) patients were taken to surgery. Patients with worsening clinical and/or laboratory findings during treatment with Regimen 1 or 2 were taken to emergency surgery.

Surgery options included unilateral salpingo-oopherectomy or total abdominal hysterectomy and bilateral salpingooophorectomy.

Patients of the study group were divided into two groups:

Group 1: Patients who responded well to medical treatment.

Group 2: Patients who did not respond to medical treatment and needed surgical treatment.

In this study, clinical, laboratory and sonographic parameters were taken into consideration as the predictive values for the success of medical treatment in Group 1 and requirement for surgery in Group 2 in the first place. Secondly, success of the medical treatment regimens was also evaluated. Patients of the Group 2 responding well to medical treatment were evaluated for the factors affecting the duration of medical therapy.

Statistical Analayzes: SPSS 18.0 was used for the statistical analysis. Kolmogorov-Smirnov test was used to determine if distribution of continuous variables was normal. Independent sample t-test was used for normallydistributed variables, and the Mann-Whitney U test was used for abnormally distributed variables. Relative risks (RRs) with $95 \%$ confidence intervals (CIs) were calculated. Level of statistical significance was accepted as the value of $p<0.05$. A receiver operating characteristic was used to evaluate cut-off, positive predictive values, and negative predictive values.

\section{Results}

Ninety-four patients in total were hospitalized with the diagnosis of TOA. The all patients firstly received the Regimen 1. Six $(6.38 \%)$ of these 94 patients were found to have acute abdominal findings, and were taken to emergency surgery while taking Regimen 1 . Recovery was achieved with Regimen 1 in 67 (71.2\%) patients out of 94 patients. Regimen 1 failed in $21(22.3 \%)$ patients and Regimen 2 was shifted to. Six patients $(28.5 \%)$ out of 21 underwent surgery because of treatment failure with Regimen 2. Recovery was achieved in the remaining 15 (71.4\%) patients. Number of patients who underwent surgery was 12 in total. 8 underwent unilateral salpingooopherectomy and 4 underwent total abdominal hysterectomy and bilateral salpingo-oopherectomy (Figure 1).

The overall total success rate of the medical treatment was found as $87.2 \%$ (82/94) with $71.2 \%$ (67/94) and 71.4\% $(15 / 21)$ success rates for Regimens 1 and 2, respectively. The average age, smoking, previous surgery in history, length of hospital stay and failure of Regimen 1 were similar in Groups 1 and 2.

The mean gravida number in both groups were $2.8 \pm 1.7$ and $3.5 \pm 3.1$, respectively $(\mathrm{p}=0.04)$, while the same for parity were $2.6 \pm 1.2$ and $3.6 \pm 2.3$, respectively $(\mathrm{p}=0.003)$. Venereal disease in history was positive in $40.4 \%$ and $75 \%$, in Groups 1 and 2, respectively ( $\mathrm{p}=0.003)$. The IUD usage of 
the groups was determined as $76.1 \%$ and $83.3 \%$, respectively $(\mathrm{p}=0.009)$. The mean abscess diameter measured in groups 1 and 2 was $4.7 \pm 0.9$ and $6.9 \pm 1.2 \mathrm{~cm}$, respectively $(\mathrm{p}=0.000)$. The mean body temperature in group 1 and 2 was $37.3 \pm 0.6{ }^{\circ} \mathrm{C}$ and $38.7 \pm 0.3{ }^{\circ} \mathrm{C}$, respectively $(\mathrm{p}=0.000)$. The mean $\mathrm{WBC}$ count was $10.430 \pm 3.290$ in Group 1 and $18.260 \pm 2.860 \mathrm{~K} / \mathrm{uL}$ in Group $2(\mathrm{p}=0.000)$. The mean CRP levels in Groups 1 and 2 were $42.5 \pm 39.8$ and $78 \pm 11.4$ respectively $(p=0.001)$. The ESR rate was significantly different between the two groups with $52.2 \pm 9.5$ in Group 1 and $82.4 \pm 11.2$ in Group 2 ( $\mathrm{p}=$ 0.000) (Table 1). Analysis of the groups' neutrophil/lymphocyte ratio (NLR) values showed that the

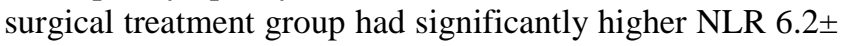
5.3 and $9.4 \pm 5.1$, respectively $(\mathrm{p}=0.001)$. As regards the factors affecting the duration of medical treatment, body temperature, previous pelvic surgery, smoking, parity and venereal diseases were similar among patients with periods of medical treatment exceeding 10 days and among patients with periods of medical treatment equal to or less than 10 days (both groups were treated medically) (Table 2). Also, longer duration of medical treatment was correlated with average age, average dimension of the abscess, medical drug exchange, gravidity, high leukocyte values, CRP levels, high NLR, ESR rate and intrauterine device (IUD) $(\mathrm{p}=0.001,0.04$, $0.000,0.005,0.000,0.000,0.001$ and 0.01 , respectively) (Table 2). Parameters predicting the requirement for surgery were also evaluated. WBC levels $\geq 16.000$ and abscess size $\geq 7 \mathrm{~cm}$ was strongly correlated with the requirement for surgery (PPV 92.6\% and 98.1\% respectively). The positive predictive value of Age $>36$ was $71.7 \%$, the same for body temperature $\geq 38.5^{\circ} \mathrm{C}$ was $78.1 \%$, for NLR> 6 it was $73.4 \%$ (Table 3).

Table1: Comparison of medical treatment and surgical treatment in patients diagnosed with TOA

\begin{tabular}{lccc} 
& $\begin{array}{c}\text { Medical treatment } \\
\text { (Grup 1, n=84) }\end{array}$ & $\begin{array}{c}\text { Surgical treatment } \\
(\text { Grup 2, n= 12) }\end{array}$ & p value \\
Age & $33.5 \pm 9.6$ & $37.1 \pm 4.2$ & 0.09 \\
Gravidity & $2.8 \pm 1.7$ & $3.5 \pm 3.1$ & $\mathbf{0 . 0 4}$ \\
Parity & $2.6 \pm 1.2$ & $3.6 \pm 2.3$ & $\mathbf{0 . 0 0 3}$ \\
Smoking & $41(48.8 \%)$ & $7(58.3 \%)$ & 0.1 \\
Previous Pelvic Surgery & $22(26.1 \%)$ & $4(33.3 \%)$ & 0.09 \\
Previous Sexually Transmitted Diseases & $34(40.4 \%)$ & $9(75 \%)$ & $\mathbf{0 . 0 0 3}$ \\
IUD & $64(76.1 \%)$ & $10(83.3 \%)$ & 0.009 \\
Duration Of Hospitalization & $8.8 \pm 2.5$ & $11.4 \pm 1.2$ & 0.08 \\
Abscess Diameter $(\mathrm{cm})$ & $4.7 \pm 0.9$ & $6.9 \pm 1.2$ & $\mathbf{0 . 0 0 0}$ \\
Body Temperature $\left({ }^{\circ} \mathrm{C}\right)$ & $37.3 \pm 0.6$ & $38.7 \pm 0.3$ & $\mathbf{0 . 0 0 0}$ \\
WBC & $10.430 \pm 3.290$ & $18.280 \pm 2.860$ & $\mathbf{0 . 0 0 0}$ \\
CRP & $42.5 \pm 39.8$ & $78 \pm 11.4$ & $\mathbf{0 . 0 0 1}$ \\
ESR & $52.2 \pm 9.5$ & $82.4 \pm 11.2$ & $\mathbf{0 . 0 0 0}$ \\
NLR & $6.2 \pm 5.3$ & $9.4 \pm 5.1$ & $\mathbf{0 . 0 0 1}$ \\
\hline Abbra
\end{tabular}

Abbreviations: IUD: Intrauterine Device, WBC: White Blood Cell (K/uL), CRP: C-Reactive Protein (mg/L), ESR: Erythrocyte Sedimentation Rate $(\mathrm{mm} / \mathrm{h})$, NLR: Neutrophil/Lymphocyte Ratio. Independent sample $t$ test and $\chi 2$ was used for normally distributed variables and the MannWhitney $\mathrm{U}$ test for abnormally distributed variables. Values are given as mean $\pm \mathrm{SD}$ or number (percentage). $\mathrm{p}<0.05$ was considered statistically significant

Table 2: Comparison of patients diagnosed with TOA on admission whose medical treatment lasted $>10$ days or $\leqslant 10$ days

\begin{tabular}{lccc} 
& $\begin{array}{c}\text { Duration of treatment } \\
\leq 10 \text { days }(\mathrm{n}: 73)\end{array}$ & $\begin{array}{c}\text { Duration of treatment } \\
>10 \text { days }(\mathrm{n}=19)\end{array}$ & $\mathrm{p}$ value \\
Age & $34.8 \pm 5.7$ & $38 \pm 6.4$ & $\mathbf{0 . 0 0 1}$ \\
Medical drug exchange & $8(9.8 \%)$ & $13(68.4 \%)$ & $\mathbf{0 . 0 0 0}$ \\
Abscess diameter $(\mathrm{cm})$ & $5 \pm 1.1$ & $5.4 \pm 1.3$ & $\mathbf{0 . 0 4}$ \\
Body Temperature $\left({ }^{\circ} \mathrm{C}\right)$ & $37.4 \pm 0.8$ & $37.7 \pm 0.9$ & 0.3 \\
Previous pelvic surgery & $32(31.4 \%)$ & $2(10.5 \%)$ & $\mathbf{0 . 0 3}$ \\
Previous sexually transmitted diseases & $46(45.1 \%)$ & $8(36.4 \%)$ & 0.5 \\
Smoking & $48(47.1 \%)$ & $10(52.6 \%)$ & 0.5 \\
Gravidity & $2.8 \pm 1.7$ & $4 \pm 1.7$ & $\mathbf{0 . 0 0 5}$ \\
Parity & $2.5 \pm 1.3$ & $3.8 \pm 1.9$ & 0.007 \\
WBC & $11.190 \pm 3.450$ & $16.740 \pm 2.460$ & $\mathbf{0 . 0 0 0}$ \\
CRP & $51.1 \pm 28.6$ & $79.5 \pm 13.1$ & $\mathbf{0 . 0 0 0}$ \\
ESR & $58.3 \pm 21.8$ & $71.3 \pm 20.1$ & $\mathbf{0 . 0 1}$ \\
NLR & $6.1 \pm 4.7$ & $9.6 \pm 8.1$ & $\mathbf{0 . 0 0 1}$ \\
IUD & $53(72.6 \%)$ & $21(100 \%)$ & $\mathbf{0 . 0 0 1}$ \\
\hline Abbrition
\end{tabular}

Abbreviations: WBC: White Blood Cell (K/uL), CRP: C-Reactive Protein (mg/L), ESR: Erythrocyte Sedimentation Rate (mm/h), NLR: Neutrophil/Lymphocyte Ratio, IUD: Intrauterine Device. Independent sample $t$ test and $\chi^{2}$ was used for normally distributed variables and the Mann-Whitney U test for abnormally distributed variables. $p<0.05$ was considered statistically significant 
Table 3: The predictive values of surgery requirement in patients diagnosed with TOA on admission

\begin{tabular}{lcccccc} 
& $\begin{array}{c}\text { Sensitivity } \\
\%\end{array}$ & $\begin{array}{c}\text { Specificity } \\
\%\end{array}$ & $\begin{array}{c}\text { PPV } \\
\%\end{array}$ & $\begin{array}{c}\text { NPV } \\
\%\end{array}$ & $\begin{array}{c}\text { P value } \\
\text { Relative risk } \\
(95 \% \mathrm{CI})\end{array}$ \\
Abscess diameter $\geq 7 \mathrm{~cm}$ & 66.5 & 98.1 & 83.6 & 92.7 & 0.000 & $10.6(2.4-52.6)$ \\
WBC count $>16 * 10^{3}$ & 87.6 & 92.6 & 76.5 & 97.4 & 0.000 & $7.54(4.9-14.2)$ \\
Age $>36$ & 44.4 & 71.7 & 26.6 & 88.3 & 0.001 & $1.5(0.8-2.8)$ \\
NLR $>6$ & 71.7 & 73.4 & 66.6 & 87.3 & 0.001 & $3.2(1.8-4.9)$ \\
Body Temperature $\geq 38.5^{\circ} \mathrm{C}$ & 88.7 & 78.1 & 48 & 96.8 & 0.000 & $2.8(1.6-5.2)$ \\
\hline Abbreviations: WBC: White Blood Cell (K/uL), NLR: Neutrophil/Lymphocyte Ratio. Relative risks (RRs) with 95\% confidence intervals \\
(CIs) were calculated. Level of statistical significance was accepted as the value of p< 0.05. A receiver operating characteristic was used to \\
evaluate cut-off, positive predictive values, and negative predictive values.
\end{tabular}

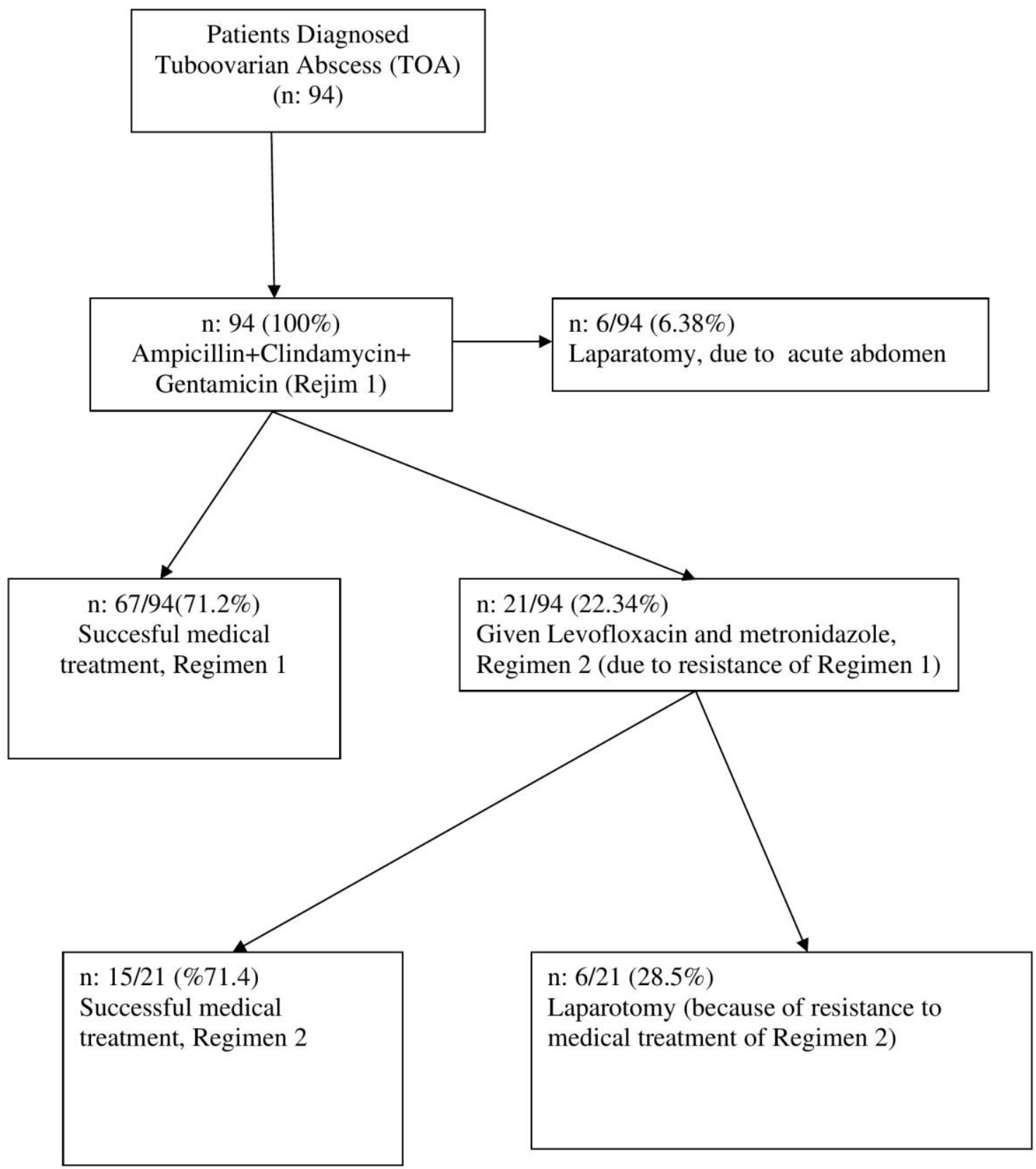

Figure 1: Flow of patients with treatment of Tuboovarian Abscess (TOA) 


\section{Discussion}

TOA treatment with antibiotics with broad spectra is successful in $34 \%$ to $87.5 \%$ of patients (6), while $25 \%$ will be taken to surgery because of resistance(12). However, superiority of any of the antibiotics to each other have not been shown yet (13). Clindamycin and metronidazole can be preferred, because they are effective on anaerobic bacteria and penetrate will into the abscess cavity (14). In a study of 232 patients, clindamycin gentamicin was reported as successful in $68 \%$ of patients (15). In another study, clindamycin+ gentamicin combination reportedly provided cure in $47 \%+$ of patients, while ampicillin+ clindamycin+ gentamicin combination was successful in $87.5 \%$ (16). Furthermore, Güngördük et al. found that clindamycin+ gentamicin or ceftriaxone+ metronidazole was successful in $74.3 \%$ of patients (17)

In our study, we found that Ampicillin ( 2 g IV every 6 hours) + Clindamycin (900 mg IV every 8 hours) + Gentamicin $(2 \mathrm{mg} / \mathrm{kg}$ loading dose then $1.5 \mathrm{mg} / \mathrm{kg}$ every 8 hours IV or IM) was effective in $71.2 \%$ of patients consistently with the reports in the literature.

The success rate of Levofloxacin (500 mg IV once daily) + Metronidazole (500 mg IV every 8 hours) regimens in resistant cases, was identified as $71.4 \%$.

The overall total success rate of medical treatments was $87.2 \%$ (82/94). These results are supportive for the continuance of medical treatment till signs or symptoms makes emergency surgery necessary.

We found no studies in the literature reporting sequential administration of the two regimens that we have used in our study. Sequential administration of these two regimens can be recommended in TOA treatment.

The predictability of the necessity for surgical treatment:

Randomized controlled trials are needed to compare these two regimes. Group1 and Group 2 were found as significantly different in Gravidity, Parity, Positive Venereal Diseases in Medical History of Patients, Abscess Size, Body Temperature, WBC, CRP, NLR and ESR rate, while differences were insignificant as regards the Age, Previous Pelvic Surgery History, IUD and Duration of Hospitalization Stay (Table 1).

In a previous study, while $35 \%$ of patients with abscesses with sizes 7 and $9 \mathrm{~cm}$ underwent surgery, $60 \%$ of patients with abscesses $60 \geq 10 \mathrm{~cm}$ underwent surgery(9).

In another study, rates of surgery in patients with abscesses with sizes $\leq 8 \mathrm{~cm}$ and $>8 \mathrm{~cm}$ were $23 \%$ and $35 \%$, respectively $(\mathrm{p}=0.24)(18)$.

Mizushima et al. reported that abscess size alone increased the probability of surgery. They found that abscess size of $>$ $5 \mathrm{~cm}$ increased the risk of surgery by 69 folds. They also found that there are no significant differences in age, gravidity, parity, body temperature, leukocyte levels and CRP levels between medical and surgical therapy groups (19). In their study, Güngördük et al, found statistically significant differences between patients treated medically or surgically as regards CRP levels, ESR, and abscess diameter $\geq 7 \mathrm{~cm}$; however, differences in WBC were not significant.

In our study, the mean abscess size was $4.7 \pm 0.9 \mathrm{~cm}$ in the medical therapy group and $6.9 \pm 1.2 \mathrm{~cm}$ in the surgical treatment group $(\mathrm{p}=0.000)$. Surgery was performed in $83.6 \%$ (RR (95\% CI) 10.6 (2.4-52.6)) of the patients with an abscess size of $\geq 7 \mathrm{~cm}$ (Table 3 ), indicating that abscesses larger than $7 \mathrm{~cm}$ require surgery.

The need for surgery is frequently linked to the abscess size. In our study however, Age, WBC, Body Temperature, NLR levels were found associated with the requirement for surgery in addition to abscess size, with mean WBC level being highly significant. Surgery was required in $76.5 \%$ $(\mathrm{RR}(95 \% \mathrm{CI}) 7.54$ (4.9-14.2)) of the patients with $\geq 16.000$ baseline leukocyte count. Based on these results, the most important factors in the patient's surgery risk were WBC level and abscess size.

\section{Conclusion}

The results of this study showed the success rate of the treatment regimen of Ampicillin ( 2 g IV every 6 hours) + Clindamycin (900 mg IV every 8 hours) + Gentamicin (2 $\mathrm{mg} / \mathrm{kg}$ loading dose then $1.5 \mathrm{mg} / \mathrm{kg}$ every 8 hours IV or IM) to be $71.2 \%$, the success rate of Levofloxacin $(500 \mathrm{mg}$ IV once daily) + Metronidazole (500 mg IV every 8 hours) regimens in resistant cases was $71.4 \%$ and the total success rate of medical treatment was $87.2 \%$.

The most important markers in the prediction of surgical treatment were determined as WBC count and abscess diameter. If abscess diameter is $\geq 7 \mathrm{~cm}$ and $\mathrm{WBC} \geq 16.000$, the risk of a need for surgical intervention is high. The most important factors in the duration of medical treatment were found to be age, WBC count, CRP and NLR levels.

\section{Acknowledgments: None}

Conflict of Interest: The authors declare no potential conflicts of interest with respect to the research, authorship, and/or publication of this article.

Author's Contributions: BÇ, ÇŞ; Research concept and design, Research the literature, preparation of the article BÇ; Revision of the article.

\section{References}

1. Inal ZO, Inal HA, Gorkem U. Experience of Tubo-ovarian abscess: a retrospective clinical analysis of 318 patients in a single tertiary Center in Middle Turkey. Surgical infections. 2018;19(1):54-60.

2. Tokmak A, Esercan A, Sarikaya E. An incidental finding of chronic salpingitis complications: Tubo-uterine fistula. Journal of experimental therapeutics \& oncology. 2015;11(2).

3. Rosado F. Factors Associated with Chlamydia trachomatis Reinfection Among Puerto Rican Adolescents 2008-2012. 2014.

4. Lachiewicz MP, Nair N. Simple Technique for Transvaginal Aspiration of a Tubo-Ovarian Abscess. Gynecologic and obstetric investigation. 2016;81(4):381-4.

5. Chu L, Ma H, Liang J, Li L, Shen A, Wang J, et al. Effectiveness and adverse events of early laparoscopic therapy versus conservative treatment for Tubo-ovarian or pelvic abscess: a single-center retrospective cohort study. Gynecologic and obstetric investigation. 2019:1-9. 
6. Granberg S, Gjelland K, Ekerhovd E. The management of pelvic abscess. Best practice \& research Clinical obstetrics \& gynaecology. 2009;23(5):667-78.

7. Lareau SM, Beigi RH. Pelvic inflammatory disease and tubo-ovarian abscess. Infectious disease clinics of North America. 2008;22(4):693-708.

8. Yavuzcan A, Çağlar M, Dilbaz S, Kumru S, Avcığlu F, Üstün Y. Identification of Clostridium septicum in a tubo-ovarian abscess: a rare case and review of the literature. Vojnosanitetski pregled. 2014;71(9):884-8.

9. Chappell CA, Wiesenfeld HC. Pathogenesis, diagnosis, and management of severe pelvic inflammatory disease and tuboovarian abscess. Clinical obstetrics and gynecology. 2012;55(4):893-903.

10. Scharbo-DeHaan M, Anderson DG. The CDC 2002 guidelines for the treatment of sexually transmitted diseases: implications for women's health care. Journal of midwifery \& women's health. 2003;48(2):96-104.

11. Workowski KA. Centers for Disease Control and Prevention sexually transmitted diseases treatment guidelines. Clinical Infectious Diseases. 2015;61(suppl_8):S759-S62.

12. Soper DE. Pelvic inflammatory disease. Obstetrics \& Gynecology. 2010;116(2):419-28
13. Kim HY, Yang JI, Moon C. Comparison of severe pelvic inflammatory disease, pyosalpinx and tubo-ovarian abscess. Journal of Obstetrics and Gynaecology Research. 2015;41(5):742-6.

14. Mirhashemi R, Schoell WM, Estape R, Angioli R, Averette HE. Trends in the management of pelvic abscesses. Journal of the American College of Surgeons. 1999;188(5):567-72.

15. Reed SD, Landers DV, Sweet RL. Antibiotic treatment of tuboovarian abscess: comparison of broad-spectrum $\beta$-lactam agents versus clindamycin-containing regimens. American journal of obstetrics and gynecology. 1991;164(6):1556-62.

16. McNeeley SG, Hendrix SL, Mazzoni MM, Kmak DC, Ransom SB. Medically sound, cost-effective treatment for pelvic inflammatory disease and tuboovarian abscess. American journal of obstetrics and gynecology. 1998;178(6):1272-8.

17. Güngördük K, Guzel E, Asicioğlu O, Yildirim G, Ataser G, Ark C, et al. Experience of tubo-ovarian abscess in western Turkey. International Journal of Gynecology \& Obstetrics. 2014;124(1):4550 .

18. DeWitt J, Reining A, Allsworth JE, Peipert JF. Tuboovarian abscesses: is size associated with duration of hospitalization \& complications? Obstetrics and gynecology international. 2010;2010.

19. Mizushima $\mathrm{T}$, Yoshida H, Ohi Y, Ishikawa M, Hirahara F. Evaluating the risk factors for developing resistance to parenteral therapy for tubo-ovarian abscess: A case-control study. Journal of Obstetrics and Gynaecology Research. 2013;39(5):1019-23. 